ORIGINAL ARTICLES

\title{
DISABILITY BURDEN AND ECONOMIC LOSS OF CANCER PATIENTS
}

\author{
MD. ZIAUL ISLAM ${ }^{1}$, MD. ABDUL JABBAR ${ }^{2}$, SHARMIN FARJANA ${ }^{3}$, SANJOY KUMAR CHOWDHURY $^{3}$
}

\begin{abstract}
:
The Descriptive cross sectional study was conducted over the period of $1^{\text {st }}$ July 2006 to $30^{\text {th }}$ June 2007 (one year) to estimate disability burden and economic loss incurred by cancer patients. The study was carried out among 224 cancer patients who attended the National Institute Cancer Research \& Hospital (NIRCH). Data was collected by face-to-face interview using a semi-structured questionnaire and systematic random sampling technique. Disability burden of cancer was measured in terms of years of life lived (YLD) and economic loss was estimated by health care expenditure incurred by the cancer patients. Out of all, major part (59.82\%) was male while $40.18 \%$ was female and most of them were in middle age group (40-49 years) with mean age of 49.18 (SD \pm 14.66 ) years. Most of the patients (93\%) were Muslims and majority (83\%) was married. Maximum number of patients (38.39\%) had primary level education with a large illiterate segment (27.68\%). By occupation, maximum patients were housewives (28.73\%) followed by agriculturers (25.50\%). The average family size was 4.6 (SD \pm 2.53$)$ and majority (39.28\%) was in poor income group (<Tk.5000). According to primary site, common cancers included cancer of lung (25\%) \& cervix (16.96\%) followed by cancer of breast (13.39\%), lymph node \& lymphatic (6.70\%), larynx (5.36\%), oral cavity (5.36\%), oesophagus $(4.46 \%)$, leukemia $(4.46 \%)$, bone \& cartilage (4.02\%), stomach (2.68\%), skin (2.68\%), prostate $(1.79 \%)$, liver $(0.89 \%)$, endocrine gland $(0.89 \%)$ \& caner of unknown primary origin (5.36\%). Most male cancer patients $(73.88 \%)$ had smoking habit in contrast to $7.78 \%$ female patients, which showed statistical significance $(\div 2$ test, $p<0.01)$.

Male patients shared more YLDs (64\%) than female patients (36\%), which was statistically significant ('t' test, $p<0.05)$. It was emerged that the highest YLD was shared by the active age group (63.8\%), middle-income group (40.35\%) and by poorly educated patients (69\%). Average treatment cost incurred by the cancer patients was TK. 5,773.11 ( \pm SD272.39) and it was more among the higher income, middle age and educated patients, which were statistically significant (ANOVA, $p<0.01)$. Male patients shared higher average treatment cost $(T K .7,158.65 \pm S D 337.76)$ than their female counterparts (TK.4387.57 \pm SD 207.02) and revealed statistical significance ('t' test, $p<0.01)$. Ca Lung incurred highest average treatment cost (TK.8,247.86 $\pm S D 121.43)$ followed by Ca cervix (TK.7,787.73 \pm SD118.56) and Ca breast (TK.7,183.53 \pm SD104.63). Half of the patients were treated by combination of surgery, chemotherapy \& radiotherapy and surgery being most costly (TK.8,574.96 $\pm S D$ 455.23), which was statistically significant (ANOVA, $p<0.01)$.
\end{abstract}

Key Words: Cancer, Disability burden, YLD, Economic Loss.

\section{Introduction:}

Cancer holds the second position among the noncommunicable diseases under study of World Health Organization (WHO) ${ }^{1,2}$ It is evidenced that in the developing societies, demographic transition has contributed to the increased prevalence of cancer and other non-communicable diseases. It was found that about 5 million new cases of cancer are diagnosed and
7.8 million people die of cancer every year globally, of which 3.5 million deaths occur in developing countries. ${ }^{3,4}$ On the contrary, about 17\% Disability Adjusted Life Years (DALYs) are lost in developed worlds and 9.0\% DALYs are lost in developing worlds in one year due to cancer. The GBD study specifically demarcated that epidemiological transition is occurring also in South Asia and burden of cancer is

1. Principal Investigator \& Asstt. Professor, Department of Community Medicine, National Institute of Preventive \& Social Medicine (NIPSOM), Mohakhali, Dhaka.

2. Head, Department of Community Medicine, Dhaka Medical College.

3. MBBS Student (Batch: K-60), Dhaka Medical College, Dhaka. 
increasing rapidly in Bangladesh. ${ }^{5-7}$

It is reported that magnitude of cancer is increasing in a rapid pace globally. The disease poses huge burden of mortality and morbidity. ${ }^{8-10}$ magnitude of cancer has also increased among the countries of South East Asia region. ${ }^{11-14}$ About 2 million new cases of cancer are diagnosed each year and 10 lack people are living with different types of cancer with overall incidence rate of 182 per 100,000 population in Bangladesh. Rising burden of cancer in Bangladesh will pose serious implications for the management and financing of the health sector. ${ }^{15-17}$ For this, health strategies may have to be reformed and activities of the health sector may have to be drastically reorganized in order to meet the challenges of the increasing burden of cancer along with other non-communicable diseases. ${ }^{18-19}$ Cancer causes serious economic damage to the households since medical care required against the disease is usually very expensive. Cancer exert huge economic pressure both on the household economy as well as public health sector. ${ }^{20}$ It is imperative to estimate the disability and economic burden of cancer patients as no comprehensive and rigorous study in this regard is available at present in the context of Bangladesh. The purpose of this study aims to address the issues related to burden of cancer, which will provide data essential for formulating policies and strategies to combat this burning public health problem.

\section{Rationale:}

The present study will explore disability and economic burden shared by cancer patients. The study will have profound academic and policy implications. At the academic level, it may upgrade the knowledge in the public health field by yielding information in different dimension, as there is no similar study available in context in Bangladesh. Besides, important feature of the proposed study will be that it will follow the approach and method used in the GBD study. So that it can generate a set of estimates of the patterns of disability and economic burden of cancer and may be comparable with the estimates of the same in other countries. Besides its academic significance, the study can depict useful policy implications. The study will help in prioritization of cancer comparing with other diseases prevalent in the country in terms of disability burden and economic loss of cancer patients, which will contribute to formulate effective health policy and health care financing.

\section{Materials and Methods:}

For estimation of disability burden of cancer in terms of YLD, age weight, time preference, disability weight, discount rate and age at onset of the disease were used. While to estimate the economic loss, direct cost incurred by the patients was calculated. Descriptive cross-sectional study was conducted during the period of $1^{\text {st }}$ July 2006 to $30^{\text {th }}$ June 2007 among 224 cancer patients, who attended National Institute of Cancer Research and Hospital. Data was collected by systematic random sampling technique using, which were finalized after pre-testing. Face-to-face interview $\&$ by reviewing medical documents were the techniques in this regards. Data was processed by editing \& post-coding and analyzed by SPSS software (version 15.0).

\section{Results:}

Out of 224 patients, $59.82 \%$ were male and $40.18 \%$ were female with a male: female ratio of 1.49:1.00. About $55 \%$ patients were in the age group of $40-64$ years followed by $22.77 \%$ patients in geriatric age group (e" 65 years) while the lowest (5.36\%) were in pediatric group (0-15 years) and mean age of the patients was 49.18 ( $\mathrm{SD} \pm 14.66)$ years. Most (93\%) of the patients were Muslims and \% was married (83\%). Regarding educational qualification, $38.39 \%$ patients had primary level education while $27.68 \%$ were illiterate. Around 29\% patients were housewives, followed by $25.50 \%$ agriculturers and $20.09 \%$ were service holders. Average family size was 4.6 ( $\mathrm{SD} \pm 2.5334)$ and average monthly family income was TK.8,129.88 (SD $\pm 6,809.21$ ) but majority (35.71\%) patients had monthly family income between TK. 5,001-TK.10,000.

In respect of primary site of cancer, lung cancer was $25 \%$, cervical cancer (17\%) and $13.4 \%$ was breast cancer. Among others, Ca Lymph node \& Lymphatic $(6.70 \%)$, larynx $(5.36 \%)$, oral cavity $(5.36 \%)$, oesophagus $(4.46 \%)$, leukemia $(4.46 \%)$, bone \& cartilage $(4.02 \%)$, stomach $(2.68 \%)$, skin $(2.68 \%)$, prostate $(1.79 \%)$, liver $(0.89 \%)$ and Ca endocrine gland $(0.89 \%)$ while $5.36 \%$ cancer was of unknown primary origin. It was also revealed that most of all cancers except ca cervix were more in male than female $\&$ it was statistically significant $\left(\chi^{2}\right.$ test, $\left.p<0.01\right)$. Lung cancer $(64.28 \%)$ and cervical cancer $(63.16 \%)$ were found among older patients ( ${ }^{3} 50$ years) followed by $23.21 \%$ and $26.32 \%$ were detected respectively in the middle age group (40-49 years). Beast cancer was 
predominant (53.34\%) in the middle age group followed by $20 \%$ in the older age group. All theses differences were statistically significant $\left(\chi^{2}\right.$ test, $\left.p<0.05\right)$. It was revealed that Ca larynx (33\%) and Ca oesophagus (30\%) were almost equal in the age group 40-49, e"50 years and unknown primary cancer was detected in all the age group except 16-27 years. A different feature was extracted in case of leukemia as it was only detected in the age group 0-15 years (70\%) and 16-27 years (30\%). This discrepancy was statistically significant $\left(\chi^{2}\right.$ test, $\left.\mathrm{p}<0.01\right)$. Ca Bones \& Cartilage and $\mathrm{Ca}$ endocrine gland were more common among the middle age group while Ca skin, Ca stomach and Ca prostate were predominant in the older age group. Most of the male patients (74\%) had smoking habit while most of the female patients (92\%) had no smoking habit and the findings were statistically significant $\left(\chi^{2}\right.$ test, $\mathrm{p}<0.01)$.

Disability burden of cancer was estimated in terms of YLD, which is depicted in the following Table-I. In respect of sex, large amount of YLD (64\%) was incurred by the male patients and mean YLD shared by male patients (131.72) was also higher than the female patients (110.31) and these sex differentials were statistically significant ('t' test, $\mathrm{p}<0.05$ ). More YLDs (32.55\%) was incurred by the age group 50-64 years while the age group 40-49 years shared $31.25 \%$ YLDs. The highest mean YLDs (151.20 SD0.96) was shared by the middle age group (40-49 years) while the lowest mean YLDs (95.50 \pm SD1.26) was shared by the older age group (e"65 years), which was showed statistical significance (ANOVA, $p<0.01$ ). It was revealed that the lower income group (d"TK.5,000) incurred the highest YLDs $40.92 \%$ ) than the higher income group and the difference revealed statistical significance $\left(\chi^{2}\right.$ test, $\mathrm{p}<0.01)$.

According to treatment cost, exactly half of the patients were treated by combination of surgery, chemotherapy $\&$ radiotherapy while $16.07 \%$ were treated by surgery \& chemotherapy and $15.18 \%$ by surgery\& radiotherapy. The study estimated average treatment cost TK.5,773.11 ( \pm SD272.39) and average cost was shared by surgical treatment was more (TK.8,574.96 \pm SD 455.23) than chemotherapy (TK. 8,125.24 \pm SD 398.54) \& radiotherapy (TK.4,278.34 \pm SD323.87). Average investigation cost

Table-I

Distribution of YLDs by Types of Cancer

\begin{tabular}{|c|c|c|c|c|c|}
\hline \multirow{2}{*}{ Type of Cancer } & \multirow{2}{*}{ YLDs (\%) } & \multirow{2}{*}{ Mean YLD $( \pm \mathrm{SD})$} & \multicolumn{3}{|c|}{ ANOVA } \\
\hline & & & F Value & $\mathrm{df}$ & p value \\
\hline$\overline{\text { Lung }}$ & 31.12 & $153.26(1.12)$ & 13.28 & 223 & 0.001 \\
\hline Cervix & 16.55 & $120.11(0.84)$ & & & \\
\hline Breast & 12.66 & $116.38(1.63)$ & & & \\
\hline Lymph node \& Lymphatic & 4.24 & $77.95(1.20)$ & & & \\
\hline Larynx & 4.32 & $99.28(1.34)$ & & & \\
\hline Oral Cavity & 4.68 & $107.55(1.67)$ & & & \\
\hline Unknown Primary & 4.68 & $107.55(1.56)$ & & & \\
\hline Oesophagus & 4.72 & $130.17(0.89)$ & & & \\
\hline Leukemia & 4.87 & $134.31(0.87)$ & & & \\
\hline Bones \& Cartilage & 4.35 & $133.29(1.23)$ & & & \\
\hline Stomach & 2.22 & $102.04(2.11)$ & & & \\
\hline Skin & 2.24 & $102.99(1.69)$ & & & \\
\hline Prostate & 1.85 & $127.55(1.34)$ & & & \\
\hline Liver & 0.75 & $103.42(1.56)$ & & & \\
\hline Endocrine gland & 0.75 & $103.42(0.54)$ & & & \\
\hline Total & 100.00 & $123.12(1.22)$ & & & \\
\hline
\end{tabular}


was TK.6,127.48 ( \pm SD234.72) while average food and travel cost was TK.3,857.17 ( \pm SD116.65) and TK.3,675.45 ( \pm SD105.36) [Table-2]. These differences of average costs by different categories was found statistical significant (ANOVA, $p<0.01)$. In respect of sex, male patients shared more average treatment cost (TK. 7,158.65 \pm SD337.76) than their female counterparts, who shared TK. $4387.57( \pm$ SD207.02) and the difference was statically significant $\left(\chi^{2}\right.$ test, $p<0.05$ ). It was found that highest average treatment cost (TK.8,247.86 \pm SD121.43) was shared by the lung cancer patients followed by TK.7,787.73 \pm SD118.56 and TK.7,183.53 \pm SD104.63 were shared by Ca cervix and Ca breast patients respectively [Table-3] and the disparities showed statistical significance (ANOVA, $\mathrm{p}<0.001)$.

The study revealed that higher income group (>TK.20,000) shared more treatment cost
(TK.9,454.82 \pm SD101.22) than the lower income group (TK. $<2,000)$ who incurred the lowest treatment cost $(3,061.77 \pm$ SD 115.08) [Figure 1] and this gap was statistically significant (ANOVA, $p<0.01$ ). Older age group shared more average treatment cost (TK.10,811.92 \pm SD109.11), than the middle age \& younger age group who shared TK.8,637.38 $( \pm \mathrm{SD} 117.18)$ and TK.1812.35 ( \pm SD111.12) respectively and the differences were significant statistically (ANOVA, $p<0.01$ ). Average treatment cost was more among the master and the graduate patients who shared TK.8,693.17 ( \pm SD110.29) and TK.7,297.29 $( \pm$ SD106.73) respectively. On the contrary, illiterate patients incurred the lowest cost (TK.3,257.77 \pm SD103.12) followed by TK. 3,326.35 $( \pm$ SD111.24) and TK. 3,560.37 ( \pm SD105.64) was shared by the patients having primary and secondary education respectively. These differences were highly significant statistically (ANOVA, $\mathrm{p}<0.01$ ).

\section{Table-II}

Different Types of Treatment Cost (Average) Shared by Cancer Patients

\begin{tabular}{lrccc}
\hline Types of Treatment Cost & Average Cost (TK.) $( \pm$ SD) & \multicolumn{3}{c}{ ANOVA } \\
\cline { 3 - 4 } & & Fvalue & df & P value \\
\hline Cost for Surgery & $8,574.96(455.23)$ & 14.24 & 223 & 0.001 \\
Cost for Chemotherapy & $8,125.24(398.54)$ & & \\
Cost for Radiotherapy & $4,278.34(323.87)$ & & \\
Cost of Investigation & $6,127.48(234.72)$ & & \\
Cost of Food & $3,857.17(116.65)$ & & \\
Travel Cost & $3,675.45(105.36)$ & & & \\
\hline
\end{tabular}

Average Treatment Cost: TK.5,773.11 (SD \pm 272.39$)$

Table-III

Distribution of Average Treatment Cost by Types of Cancer

\begin{tabular}{lrcc}
\hline Type of Cancer & Average Cost (TK) $( \pm$ SD) & \multicolumn{3}{c}{ ANOVA } & df & p value \\
\cline { 3 - 4 } & & F Value & 13.66 \\
Lung & $8,247.86(121.43)$ & & \\
Cervix & $7,787.73(118.56)$ & & \\
Breast & $7,183.53(104.63)$ & & \\
Lymph node \& Lymphatic & $4,030.88(128.98)$ & & \\
Larynx & $6,762.82(139.07)$ & & \\
Oral Cavity & $6,398.83(135.65)$ & & \\
Unknown Primary & $4,396.85(127.45)$ & & \\
Oesophagus & $4,896.85(129.83)$ & & \\
Leukemia & $4,463.87(138.34)$ & & \\
Bones \& Cartilage & $4,731.93(137.23)$ & & \\
Stomach & $6,558.74(147.25)$ & & \\
Skin & $3,472.54(144.47)$ & & \\
Prostate & $6,298.25(136.39)$ & & \\
Liver & $6,519.58(138.72)$ & & \\
Endocrine gland & $4,846.39(122.32)$ & & \\
\hline
\end{tabular}




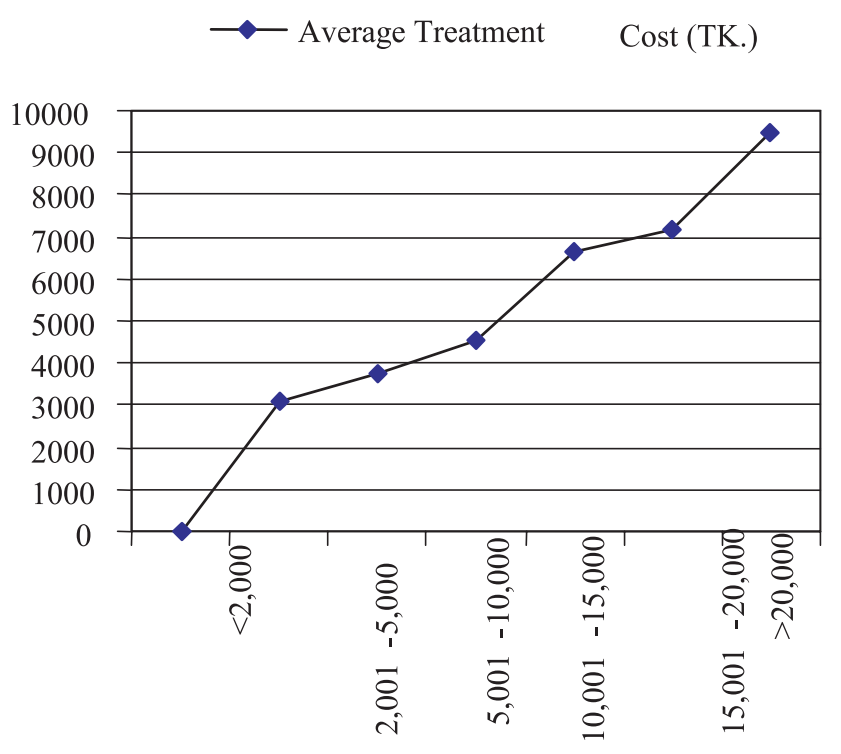

Monthly Family Income

Fig-1: Distribution of Average Treatment Cost by Monthly Family Income

\section{Discussion:}

This specific descriptive cross-sectional study was conducted with cancer patients at the National Institute of Cancer Research and Hospital, Bangladesh to estimate disability burden and economic loss posed by cancer. Mean age of cancer patients was 49.18 $(\mathrm{SD} \pm 14.66)$ years and majority of them (54.91\%) was in the age group $40-64$ years and $22.77 \%$ were in geriatric group (e" 65 years) while the least (5.36\%) patients were in pediatric group (0-15 years). The NICRH reported very close findings as the mean age was 48.21 ( $\mathrm{SD} \pm 16.79)$ years and majority of the patients $(44.50 \%)$ were in the age group 40-59 years while the lowest number of patients $(2.2 \%)$ were in pediatric group (0-9 years) followed by $3.9 \%$ in $10-19$ years group. The study detected $25 \%$ lung cancer followed by $16.96 \%$ cervical cancer and $13.39 \%$ breast cancer. On the contrary, The NICRH reported cancer of lung (16.7\%), cervix (10.4\%), breast (10.3\%), lymph nodes \& lymphatic (5.5\%), larynx (5.0\%), oesophagus $(4.0 \%)$, oral cavity $(3.9 \%)$, bones \& cartilage $(3.3 \%)$ stomach $(3.1 \%)$, skin $(2.6 \%) \& 6.2 \%$ of unknown primary cancer. The differences of frequencies of primary sites of cancer may due to variation of sample size as this study was conducted among 224 cancer patients only while NICRH considered 7,516 new patients in 2005 .

It was reflected that among lung cancer patients, $89.29 \%$ were male while among breast cancer patients,
$86.67 \%$ were female. It was also revealed that most of the cancers were predominant among male except cervical cancer. This sex variation of cancer was found statistically significant $\left(\chi^{2}\right.$ test, $\left.\mathrm{p}<0.01\right)$. Similar findings were revealed by the annual report of NICRH. In respect of age of the patients, lung cancer (64.28\%) and cervical cancer (63.16\%) were found among older patients (e"50 years). On the other side, breast cancer was predominant (53.34\%) in the middle age group (40-59 years) and this variation of cancer occurrence by age groups was statistically significant $\left(\chi^{2}\right.$ test, $\mathrm{p}<0.01)$. It was depicted that among the male patients, most (74\%) had smoking habit while among the female patients; majority (92\%) had no smoking habit. This association between smoking habit by sex was statistically significant $\left(\chi^{2}\right.$ test, $\left.\mathrm{p}<0.01\right)$. These findings were very close to the annual report of NICRH.

The study estimated total 27,578.27 YLDs, and 123.12 $(\mathrm{SD} \pm 1.22)$ mean YLDs. Out of total, lung cancer shared more (31.12\%) YLDs followed by cervical cancer (16.55\%) and breast cancer shared $12.66 \%$ YLDs. In this respect, there was no relevant study available in context of Bangladesh to compare. But the findings are different from the findings of global disease burden (GBD) study carried out by Murray and Lopez as that was conducted globally while this study was conducted in a hospital setting of Bangladesh. ${ }^{2,3}$ More YLDs (64\%) was incurred by the male than female cancer patients (36\%) and the difference was statistically significant ('t' test, $\mathrm{p}<0.05$ ). It was also revealed that more mean YLDs (151.20 \pm SD 0.96$)$ was shared by the age group 40 - 49 years than the 50-64 years age group (136.01 \pm SD1.21) and the difference was statistically significant (ANOVA, $\mathrm{p}<0.01$ ). Mean YLDs estimated by this study was lower than that revealed by the GBD study. ${ }^{2,3}$ The study extracted that $40.92 \%$ YLDs was shared by the lower income group (d"TK.5,000), 40.35\% by middle income group (TK.5,001-TK.10,000) while only $18.73 \%$ YLDs was shared by higher income group (e"TK.10,000). These discrepancies of YLDs sharing among different income groups were statistically significant (ANOVA, $\mathrm{p}<0.01)$. Mean YLD shared by the patients with primary education was $129.52( \pm \mathrm{SD} 1.19)$ while it was $125.12( \pm$ SD 1.20) among the illiterate patients and the difference showed statistical significance (ANOVA, $\mathrm{p}<0.01)$ but disparities were observed compared with the GBD study conducted by Murray and Lopez. ${ }^{2,3}$ 
For estimation of treatment cost, only direct cost was considered and average treatment cost was estimated TK.5,773.11 ( \pm SD272.39). The study conducted Greenwald P et al in USA showed higher cost for hospital care than cost for drug, food and investigation. Moreover the study found more indirect cost shared by cancer patients than direct cost. It was also depicted that educated patients shared higher average treatment cost than illiterate patients, which was statistically significant (ANOVA, $\mathrm{p}<0.01$ ). The reasons behind this may be the educated patients were more aware and they spent more for investigations and treatment of cancer.

\section{Conclusion:}

The descriptive cross-sectional study was carried out with a view to estimate disability burden and economic loss shared by cancer patients. According to primary site, common cancers included cancer of lung, cervix, breast, lymph node \& lymphatic, larynx, oral cavity, oesophagus, bone \& cartilage, stomach, skin, prostate, liver, of unknown primary origin and leukaemia. Most of the lung cancer patients were male, who were mostly smokers while most of the female patients were mostly non-smokers and had Ca cervix. Ca lung and Ca cervix were predominant among older patients but Ca breast was predominant in the middle age group. Regarding disability burden, Ca lung shared highest mean YLDs followed by Ca cervix \& Ca breast. Male patients shared more YLDs than female patients. It was emerged that the middle age group, lower income group and poorly educated patients shared more mean YLDs.

Regarding treatment, half of the patients were treated by combination of surgery, chemotherapy \& radiotherapy. The highest average treatment cost was incurred by surgery followed by chemotherapy, radiotherapy \& lab investigation. Male patients incurred more treatment cost than their female counterparts. Ca Lung incurred the highest average treatment cost tenured by Ca cervix and Ca breast. Middle \& older age group shared the more treatment cost than younger patients. It was also focused that the highest average treatment cost was shared by higher income group and educated patients. The study findings will play a crucial role in policy making to combat the disability \& economic burden of cancer in context of Bangladesh.

\section{References:}

1. The World Health Report 1999. The double burden: emerging epidemics and persistent problem. Geneva, World Health Organization, 1999: 13-16.

2. World Health Organization (WHO). World Cancer Report 2005.

3. World Health Organization (WHO). World Cancer Report 2003. Edited by Bernard W, Stewart and Kleihues P. Geneva, 2003.

4. World Health Organization (WHO). Cancer: Causes and Prevention and Control Strategy 2006. Media Centre, WHO, 2007.

5. Murray CJL, Lopez AD. The global burden of disease: a comprehensive assessment of mortality and disability from diseases, injuries, and risk factors in 1990 and projected to 2020. Cambridge: Harvard University Press, 1996: 250-287.

6. Murray CJL, Lopez AD. Global comparative assessments in the health sector. Disease burden, expenditures and intervention packages World Health Organization, Geneva, 1994.

7. Brundtland GH. Speech on Burden of Disease Concept. World Health Organization, Geneva, 1998.

8. World Health Organization (WHO). World Cancer Report. Geneva, 2000. Sourc:http:// www.who.int/mediacentre/news/releases/2003/pr27/ en/print.html.

9. GLOBOCAN. Cancer Incidence, Mortality and Prevalence Worldwide. 2000. htt: //www dep.iarc.fr./ globocan/globocan.html.

10. Parkin DM, Pisani P, Ferlay J. Global Cancer Statistics. CA CANCER J CLIN1999; 49:33-64.

11. Park K. Park's Textbook of Preventive and Social Medicine. Nineteenth Edition. M/s Banarsaidas Bhanot Publishers, Prem Nagar, Jabalpur, India, 2007: 318-320.

12. South East Asia Regional Office (SEARO). Noncommunicable diseases Prevention and Management. New Delhi, India, 2002: 1-14.

13. World Health Organization (WHO). Health Situation in South East Asia Region 1998-2000. New Delhi, India, 2002.

14. RAND. Policy and Health in Asia: Demographic and Epidemiological Transitions. Policy Brief and Population Matters, 2000. 
JM Vol. 9, No. 1

15. Ministry of Health and Family Welfare, Government of the Peoples' Republic of Bangladesh. Health, Nutrition and Population Sector Programme (2003-2006). Dhaka, Bangladesh, 2003.

16. Department of Cancer Epidemiology, National Institute of Cancer Research \& Hospital. Annual Report 2005. Dhaka, Bangladesh 2005:1-17.

17. Rahman SMA, Alam AMMS, Rahman AKMH. Principles of Treatment of Cancers in Training Manual 2003. National Institute of Cancer Research and Hospital (NICRH), Bangladesh 2003:34-36.
Disability Burden and Economic Loss of Cancer Patients

18. Frank J. Health transition in middle-income countries: new challenges for health care. Health Policy Planning 1989; 4: 29-39.

19. Rashid KM, Rahman M, Hyder S. Textbook of Community Medicine and Public Health. Fourth Edition. RHM Publishers, Banani, Dhaka, Bangladesh 2004: 288-295.

20. Witter S. The use of cost information. In Witter S, Ensor T, Jowett Mand Thompson R. Health Economics for developing Countries, A practical guide. The University of York, MACMILLAN EDUCATION LTD, London and Oxford, 2000: 105-109. 